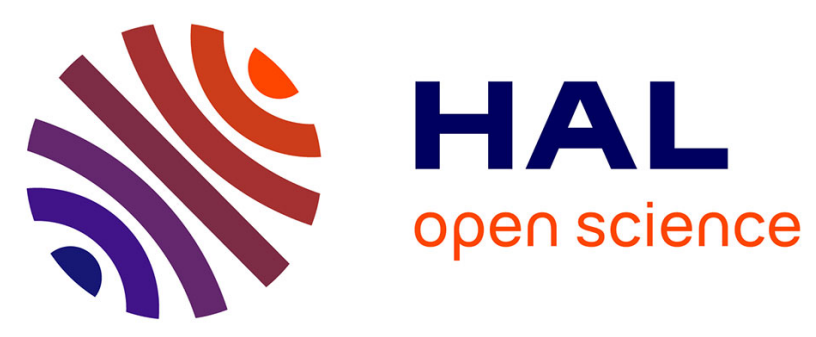

\title{
Magnetotransport and specific heat properties in the charge density wave state of the quasi two-dimensional bronzes (P02)4(W03)2m(m=4,6,7)
}

J. Lehmann, C. Schlenker, C. Le Touze, A. Rotger, J. Dumas, J. Marcus, Z. Teweldemedhin, M. Greenblatt

\section{To cite this version:}

J. Lehmann, C. Schlenker, C. Le Touze, A. Rotger, J. Dumas, et al.. Magnetotransport and specific heat properties in the charge density wave state of the quasi two-dimensional bronzes (P02)4(W03)2m(m = 4,6,7). Journal de Physique IV Proceedings, 1993, 03 (C2), pp.C2-243-C2-246. 10.1051/jp4:1993248 . jpa-00251331

\section{HAL Id: jpa-00251331 https://hal.science/jpa-00251331}

Submitted on 1 Jan 1993

HAL is a multi-disciplinary open access archive for the deposit and dissemination of scientific research documents, whether they are published or not. The documents may come from teaching and research institutions in France or abroad, or from public or private research centers.
L'archive ouverte pluridisciplinaire HAL, est destinée au dépôt et à la diffusion de documents scientifiques de niveau recherche, publiés ou non, émanant des établissements d'enseignement et de recherche français ou étrangers, des laboratoires publics ou privés. 


\title{
Magnetotransport and specific heat properties in the charge density wave state of the quasi two-dimensional bronzes $\left(\mathrm{PO}_{2}\right)_{4}\left(\mathrm{WO}_{3}\right)_{2 \mathrm{~m}}$ $(\mathrm{m}=4,6,7)$
}

\author{
J. LEHMANN, C. SCHLENKER, C. LE TOUZE, A. RÖTGER, J. DUMAS, J. MARCUS, \\ Z. TEWELDEMEDHIN* and M. GREENBLATT*
}

Laboratoire d'Etudes des Propriétés Electroniques des Solides, Associé à l'Université Joseph Fourier, CNRS, BP. 166, 38042 Grenoble cedex 9, France

* Department of Chemistry, Rutgers, The State University of New Jersey, Piscataway, NJ 08855-0939, U.S.A.

\begin{abstract}
Hall effect and specific heat have been measured on single crystals of $\mathrm{P}_{4} \mathrm{~W}_{8} \mathrm{O}_{32}, \mathrm{P}_{4} \mathrm{~W}_{12} \mathrm{O}_{44}$ and $\mathrm{P}_{4} \mathrm{~W}_{14} \mathrm{O}_{50}$. The Hall constant is small in the high temperature normal state and $\left|\mathrm{R}_{\mathrm{H}}\right|$ increases at the Peierls transitions, corroborating the existence of charge density wave gap openings. Specific heat data show that the Debye temperature is in the range $240 \mathrm{~K}-280 \mathrm{~K}$. Anomalously large $\gamma$ coefficients of the linear contribution to the specific heat are found. In the case of $\mathrm{P}_{4} \mathrm{~W}_{14} \mathrm{O}_{50}$, an anomaly found around $45 \mathrm{~K}$ provides values of the enthalpy and entropy changes at the low temperature transition.
\end{abstract}

\section{Introduction}

Among the low dimensional transition metal oxides or chalcogenides, the quasi two-dimensional (2D) systems have aroused a new interest these last years in relation with the properties of the high $\mathrm{T}_{\mathrm{c}}$ superconducting copper based oxides. The mechanisms which determine why a superconducting or a charge density wave (CDW) instability is established are not well understood at the moment. In this context, it is worthwhile to investigate new 2D systems in details. The monophosphate tungsten bronzes, $\left(\mathrm{PO}_{2}\right)_{4}\left(\mathrm{WO}_{3}\right)_{2 \mathrm{~m}}$, are good candidates for such studies, since in this case one can vary the low dimensional character by changing the chemical formula, without changing the filling of the conduction band[1]. These materials were synthesized and their crystal structure studied more than ten years ago[2][3]. They are built with perovskite-type $\left(\mathrm{ReO}_{3}\right)$ infinite layers of $\mathrm{WO}_{6}$ octahedra. Due to electron transfer between $\mathrm{PO}_{4}$ and $\mathrm{WO}_{3}$, the conduction band, built on hybridized $\mathrm{p}-\mathrm{d}$ orbitals, is partially filled. Quasi $2 \mathrm{D}$ electronic properties are induced since the conduction electrons are located in the WO 6 layers. The thickness of these layers is increasing with $\mathrm{m}$, while the number of electrons per primitive cell is always 4 , independent on $\mathrm{m}$. Anomalies in the electrical resistivity have been found in the $m=4,6$ and 7 members [4-6]. X-ray diffuse scattering studies have established that CDW-type instabilities take place in all these compounds[7]. In all cases, the satellite peak wave vector is found incommensurate with the average lattice. For $\mathrm{m}=4$ and $m=6$, two successive instabilities are found, with Peierls temperatures $T_{p 1} \simeq 80 \mathrm{~K}, T_{p 2} \simeq 50 \mathrm{~K}$ and $T_{\mathrm{p} 1} \simeq$ $120 \mathrm{~K}, \mathrm{~T}_{\mathrm{p} 2} \simeq 60 \mathrm{~K}$ respectively. They correspond to metal-metal transitions, each instability destroying parts of the Fermi surface according to the nesting wave vector. For $m=7$, two transitions are also found at $\mathrm{T}_{\mathrm{pl}} \simeq 188 \mathrm{~K}$ and $\mathrm{T}_{\mathrm{p} 2} \simeq 60 \mathrm{~K}$. In this case, the satellite peaks show several harmonics, thus indicating that the CDW modulation is not sinusoidal[7]. Furthermore, the transport properties are peculiar and not characteristic of "classical" CDW transitions[6]. Band structure calculations using a tight binding extended Hückel method lead to three bands crossing the Fermi level, one corresponding to quasi-1D Fermi surface (FS), the others to quasi 2D ones[8]. The concept of "hidden nesting" also suggests to consider the 2D FS as the combination of two $1 \mathrm{D}$ ones, due to a weak hybridization between the relevant $\mathrm{W}-\mathrm{O}$ infinite chains. We have previously shown that quasi $2 \mathrm{D}$ systems often show giant positive anisotropic magnetoresistance in the CDW state, due to the presence of small electrons and holes pockets left by the CDW gap openings[9,10]. This is the case in the low temperature state of the $m=4$ and 6 compounds[6]. We now report Hall effect and magnetoresistance data obtained on the three phases $m=4,6$ and 7, in order to get 
more insight into the transport properties. We also report specific heat measurements giving for the first time thermodynamic information on these series.

\section{Experiment}

Single crystals used in these studies have been grown by solid state reaction[4] or by chemical vapor transport technique[5]. The crystals are in shape of platelets, parallel to the (ab) conducting plane, of typical size $1 \times 1.5 \times 0.1 \mathrm{~mm}^{3}$. The transport properties have been measured between $4.2 \mathrm{~K}$ and $300 \mathrm{~K}$, in fields up to $6 \mathrm{~T}$ with the current passed in the ab plane, the magnetic field being parallel to c. Indium contacts were deposited on the cleaved surfaces. Specific heat has been measured on small single crystals (i $2 \mathrm{mg}$ weight), between $1.8 \mathrm{~K}$ and $50 \mathrm{~K}$, with a home-built microcalorimeter, using a relaxation technique.

Fig. 1a and $\mathrm{b}$ show the magnetotransport properties of $\mathrm{P}_{4} \mathrm{~W}_{8} \mathrm{O}_{32}(\mathrm{~m}=4)$. In zero magnetic field, the two CDW transitions appear as bumps on the curves of the resistivity vs temperature. Large magnetoresistance is found below $T_{p 2}$. The Hall constant $R_{H}$ is found small and positive in the high temperature phase $\left(T>T_{p 1}\right)\left(R_{H}=2 \times 10^{-10} \mathrm{~m}^{3} \mathrm{C}^{-1}\right)$. In the intermediate phase $\left(\mathrm{T}_{\mathrm{p} 2}<\mathrm{T}<\mathrm{T}_{\mathrm{p} 1}\right), R_{\mathrm{H}}$ changes sign. Below $T_{\mathrm{p} 2}, R_{\mathrm{H}} \mid$ increases steeply down to the lowest temperatures $\left(\left|R_{\mathrm{H}}\right| \stackrel{\mathrm{p} 2}{\simeq} \mathbf{1 0}^{-9} \mathrm{~m}^{3} \mathrm{C}^{-1}\right.$ at $4.2 \mathrm{~K})$. In the case of $\mathrm{P}_{4} \mathrm{~W}_{12} \mathrm{O}_{44}(\mathrm{~m}=6)$, positive magnetoresistance is also found below $\mathrm{T}_{\mathrm{p} 2}$ (Fig. 1c). Both the magnetoresistance and the conductivity are roughly one order of magnitude smaller than in the case $m=4$. The Hall constant is always found negative (Fig. $1 d$ ). $\mid R_{H} l$ is small both in the high and intermediate temperature phases. A steep increase of $\left|R_{H}\right|$ takes place below $T_{p 2}$ Values also larger than in the case $\mathrm{m}=4$ are found at low temperatures $\left(\mid R_{\mathrm{H}} \mathrm{I}=3.5 \times 10^{-8} \mathrm{~m}^{3} \mathrm{C}^{-1}\right.$ at $4 \mathrm{~K}$ ). A low temperature anomaly is found in the vicinity of $30 \mathrm{~K}\left(\mathrm{~T}_{\mathrm{p} 3}\right)$. The results obtained on $\mathrm{P}_{4} \mathrm{~W}_{14} \mathrm{O}_{50}(\mathrm{~m}=7)$ are shown on Fig. le and $1 \mathrm{f}$. As previously reported, the high temperature instability $\left(\mathrm{T}_{\mathrm{p} 1}=185 \mathrm{~K}\right)$ appears as a rapid increase of the resistivity followed by a bump at $150 \mathrm{~K}$. The low temperature Peierls transition is not observed on the resistivity curve. Magnetoresistance was however found only below $\mathrm{T}_{\mathrm{p} 2} \simeq 60 \mathrm{~K}[6]$. One should also note that thermal hysteresis is found on this sample between $180 \mathrm{~K}$ and $110 \mathrm{~K}$. In this case, the Hall constant is found always positive. It is small $\left(\simeq 3 \times 10^{-10} \mathrm{~m}^{3} \mathrm{C}^{-1}\right)$ above $\mathrm{T}_{\mathrm{p} 1}$ and increases continuously below, reaching a value of $1.6 \times 10^{-8} \mathrm{~m}^{3} \mathrm{C}^{-1}$ at $4.2 \mathrm{~K}$. Thermal hysteresis is also found between $200 \mathrm{~K}$ and $160 \mathrm{~K}$. No sign of the $T_{\mathrm{p} 2}$ instability is observed on the $R_{H}(T)$ curve.

The curves of the specific heat $C_{p}$ vs temperature are shown for the three compounds $m=4,6$ and 7 on Fig. $2 \mathrm{a}$, in the temperature interval $1.8 \mathrm{~K}-50 \mathrm{~K}$. An anomaly is found for $\mathrm{m}=7$ with a peak at $\simeq 45 \mathrm{~K}$. It might be related to the low temperature transition $T_{p 2}$. The curves of $C_{p} / T$ vs $T^{2}$ are given on Fig. $2 b$ for all three compounds, for $T<9 \mathrm{~K}$. A fit with the formula $C_{p}=\gamma T+B T^{3}$ is satisfactory in this temperature range. From the value of $\beta$, one obtains Debye temperatures in the range $240 \mathrm{~K}-280 \mathrm{~K}$ (Table I). The coefficient $\gamma$ is found to be comparatively large, in the range $100-200 \mathrm{~mJ} \mathrm{~mole}^{-1} \mathrm{~K}^{-2}$ for the three compounds.

\section{Table I}

Properties of $\left(\mathrm{PO}_{2}\right)_{4}\left(\mathrm{WO}_{3}\right)_{2 \mathrm{~m}}$ for $\mathrm{m}=4,6$ and 7. Peierls temperatures from this work. $\mathrm{R}_{\mathrm{H}}$ is the Hall

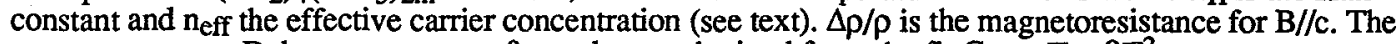
Debye temperature $\theta_{D}$ and $\gamma$ are obtained from the fit $C_{p}=\gamma T+\beta T^{3}$.

\begin{tabular}{|l|l|l|l|l|l|l|l|l|l|}
\hline Formula & $\begin{array}{l}\mathrm{T}_{\mathrm{p}} \\
(\mathrm{K})\end{array}$ & $\begin{array}{l}\rho(300 \mathrm{~K}) \\
\left(10^{-3}\right. \\
\Omega . c \mathrm{~m})\end{array}$ & $\begin{array}{l}\mathrm{R}_{\mathrm{H}}(300 \mathrm{~K}) \\
\left(10^{-9} \mathrm{~m}^{3}\right. \\
\left.\mathrm{C}^{-1}\right)\end{array}$ & $\begin{array}{l}\mathrm{n}_{\text {eff }} \\
(300 \mathrm{~K}) \\
\left(10^{28} \mathrm{~m}^{-3}\right.\end{array}$ & $\begin{array}{l}\rho \\
(10 \mathrm{~K})\end{array}$ & $\begin{array}{l}\mathrm{R}_{\mathrm{H}} \\
(10 \mathrm{~K})\end{array}$ & $\begin{array}{l}\Delta \rho / \rho \\
(6 \mathrm{~T}, 10 \mathrm{~K})\end{array}$ & $\begin{array}{l}\theta_{\mathrm{D}} \\
(\mathrm{K})\end{array}$ & $\begin{array}{l}\gamma(\mathrm{mJ} \\
\mathrm{mole}^{-1} \\
\left.\mathrm{~K}^{-2}\right)\end{array}$ \\
\hline $\begin{array}{l}\mathrm{P}_{4} \mathrm{~W}_{8} \mathrm{O}_{32} \\
\mathrm{~m}=4\end{array}$ & $\begin{array}{l}85 \\
54\end{array}$ & 0.24 & +0.25 & 2.5 & 0.015 & -8 & 2.9 & $276 \pm 17$ & $209 \pm 35$ \\
\hline $\begin{array}{l}\mathrm{P}_{4} \mathrm{~W}_{12} \mathrm{O}_{44} \\
\mathrm{~m}=6\end{array}$ & $\begin{array}{l}120 \\
60 \\
30\end{array}$ & 0.83 & -0.5 & 1.25 & 0.205 & -30.5 & 0.30 & $237 \pm 3$ & $101 \pm 6$ \\
\hline $\begin{array}{l}\mathrm{P}_{4} \mathrm{~W}_{14} \mathrm{O}_{50} \\
\mathrm{~m}=7\end{array}$ & $\begin{array}{l}183 \\
44\end{array}$ & 22 & +0.3 & 2.1 & 12.8 & +15.8 & 0.02 & $239 \pm 4$ & $136 \pm 14$ \\
\hline
\end{tabular}



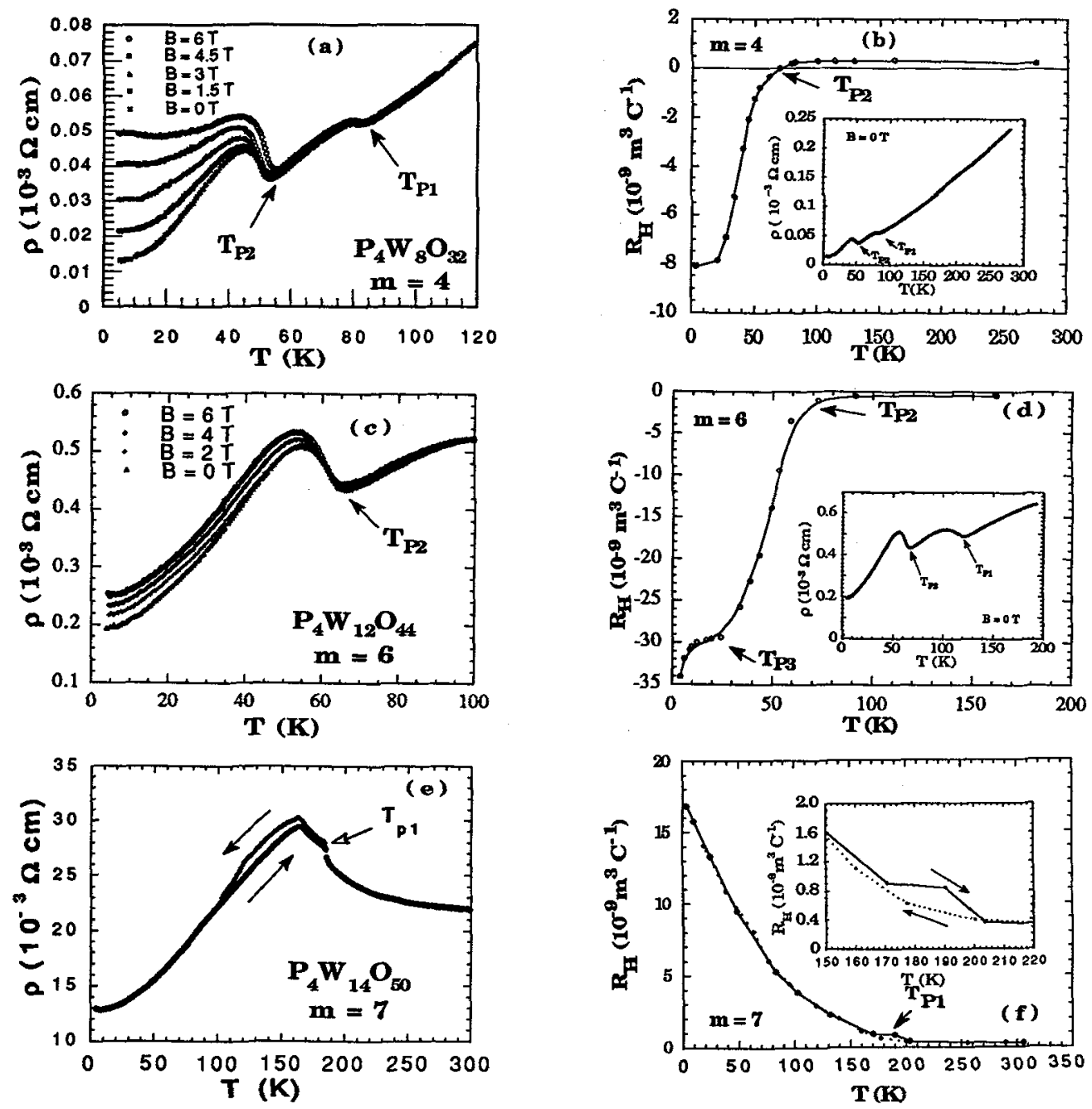

Fig. 1 - Resistivity for different values of magnetic fields and Hall constant $R_{H}$ vs temperature.

(a) and (b) : $\mathrm{P}_{4} \mathrm{~W}_{8} \mathrm{O}_{52}(\mathrm{~m}=4)$. (c) and (d) $: \mathrm{P}_{4} \mathrm{~W}_{12} \mathrm{O}_{44}(\mathrm{~m}=6)$. (e) and (f) $: \mathrm{P}_{4} \mathrm{~W}_{14} \mathrm{O}_{50}(\mathrm{~m}=7)$.
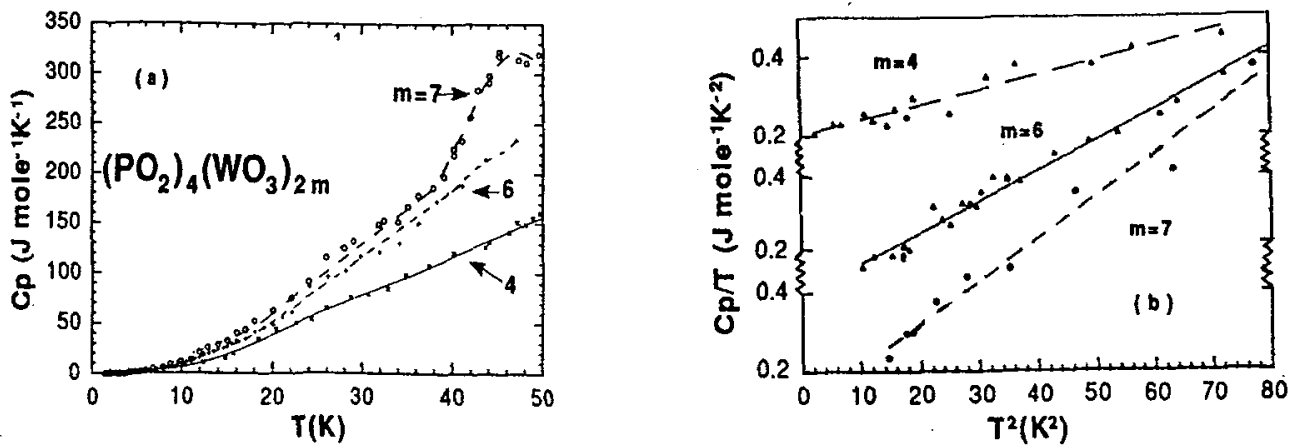

Fig. 2 (a) Low temperature specific heat $C_{p}$ as a function of temperature for the three compounds $m=4$, 6 and 7.- (b) $C_{p} / T$ vs $T^{2}$ for the three compounds $m=4,6$ and 7 . 


\section{Discussion}

The properties of the three compounds are summarized on Table I. First, one should note that for $\mathrm{m}=4$ and $\mathrm{m}=6$, the increase of the Peierls temperatures with $\mathrm{m}$, therefore with the thickness of the $\mathrm{WO}_{6}$ layers correlated to the c-parameter, may be consistent with an increased low dimensionality favoring better Fermi surface nesting. While the resistivity is larger at $300 \mathrm{~K}$ for $\mathrm{m}=6$ than for $\mathrm{m}=4$, the Hall constant is of the same order of magnitude, but with different signs. One obtains effective carrier concentrations, $\mathrm{n}_{\mathrm{eff}}=1 / \mathrm{e} \mathrm{R}_{\mathrm{H}}$, larger than the values calculated from the chemical formula by assuming an average number of $2 / \mathrm{m}$ electrons per $W$ ion $\left(0.4\right.$ to $\left.0.7 \times 10^{28} \mathrm{~m}^{-3}\right)$. The change of sign between $\mathrm{m}=4$ and 6 is puzzling. This indicates that a one-band picture is too simple and that slight changes of the band structure due to the transverse coupling along the $\mathrm{c}$ axis may be important for the transport properties. Differences in the order of magnitude of the resistivity at $300 \mathrm{~K}$ may be due to different relaxation times possibly related to different electron-phonon coupling.

Magnetotransport properties clearly support the existence of CDW gap openings at the Peierls temperatures. As previously reported[6], large positive anisotropic magnetoresistance below $\mathbf{T}_{\mathrm{p} 2}$ is due to the existence of both electrons and holes pockets left by the CDW gap openings. These pockets are expected to be quasicylindrical along the c-axis and give rise to closed orbits for Bllc. Hall effect shows that for $m=4$ and 6 , the dominant carriers are at low temperature electrons. The increase of $\left|R_{H}\right|$ at the transitions is consistent with gap openings. In the case $m=6$, it is surprising that the $T_{p 1}$ instability does not induce a measurable change of $\left|R_{H}\right|$. This may indicate that this transition corresponds to the loss of a small part of the Fermi surface only. On the other hand, a further instability found below $30 \mathrm{~K}$ is consistent with recent structural results. The smaller values of $\Delta \rho / \rho$ for increasing $\mathrm{m}$ indicate lower carrier mobilities.

The properties of $\mathrm{P}_{4} \mathrm{~W}_{14} \mathrm{O}_{50}$ seem different. First the room temperature resistivity is still one order of magnitude higher than for $m=6$, although the Hall constant value is positive and similar to the one found for $m=4$. The $T_{p 1}$ instability appears as a small anomaly only on the curve $R_{H}(T)$. The hysteresis found for increasing and decreasing temperatures, correlated to what was obtained on the curve $p(T)$, however corroborates the existence of the $T_{p 1}$ transition. The low temperature Peierls instability does not appear on the curve $R_{H}(T)$.

The specific heat data first show that the low temperature lattice excitations are similar for $\mathrm{m}=6$ and 7 , since the Debye temperature is approximately the same (Table I). In the case $m=4$, the larger Debye temperature indicates that the lattice is more rigid, which may be consistent with a weaker two-dimensional character. The comparatively high values of the $\gamma$ coefficient are puzzling. It is difficult to know at present whether this is due only to electron excitations. One cannot exclude some contribution related to defects, such as stacking faults, which appear frequently in this type of materials. If the origin of this term would be purely electronic, it could indicate that electrons correlations effects are large in this family of compounds. In the case $m=7$, the anomaly found around $44 \mathrm{~K}$ is very likely correlated to the $\mathrm{T}_{\mathrm{p} 2}$ transition[7]. The enthalpy and entropy changes are found to be $220 \pm 30 \mathrm{~J}$ mole -1 and

$5.5 \pm 0.7 \mathrm{~J} \mathrm{~mole}^{-1} \mathrm{~K}^{-1}$ respectively. Since the transport properties are not affected by this transition, this might indicate that it is mainly structural.

\section{References}

[1] GREENBLATT M., Int. J. Mod. Phys. B (to be published, 1993) (special issue on Oxide Bronzes).

[2] GIROULT J.P., GOREAUD M., LABBÉ P. and RAVEAU B., Acta Cryst. B37 (1981) 2139. DOMENGĖS B., STUDER F., RAVEAU B., Mat. Res. Bull. 18 (1983) 669.

[3] P. LABBE, M. GOREAUD and B. RAVEAU, J. Solid State Chem. 61 (1986) 234.

[4] E. WANG, M. GREENBLATT, I.E. RACHIDI, E. CANADELL, M.H. WHANGBO and S. VADLAMÁNNATI, Phys. Rev. B 39 (1989) 12969.

[5] Z.S. TEWELDEMEDHIN, K.V. RAMANUJACHARY and M. GREENBLATT, Phys. Rev. B 46 (1992) 7897.

[6] A. RÔTGER, C. SCHLENKER, J. DUMAS, E. WANG, Z. TEWELDEMEDHIN and $M$. GREENBLATT, Synth. Metals 56 (1993) 2670.

[7] P. FOURY and J.P. POUGET, Int. J. Mod. Phys. B (to be published, 1993) - P. FOURY, J.P. POUGET, E. WANG and M. GREENBLATT, Europhys. Lett. 16 (1991) 485. P. FOURY, Thesis, Université Paris-Sud (June 1993).

[8] E. CANADELL and M. WHANGBO, Phys. Rev. B 43 (1990) 1894, Chem. Rev. 91 (1991) 965 , Int. J. Mod. Phys. B (to be published).

[9] See for exemple "Low dimensional electronic properties of molybdenum bronzes and oxides", Ed. C. SCHLENKER (Kluwer Acad. Publ., 1989).

[10] J. DUMAS and C. SCHLENKER, Int. J. Mod. Phys. B (to be published, 1993). 